\title{
Erratum: Checklist of mammals from Goiás, central Brazil
}

In the article "Checklist of mammals from Goiás, central Brazil”, with the DOI code number: https://doi.org/10.1590/1676-0611-BN-2020-1173, published at Biota Neotropica 21(3): e20201173, on:

Table 1, page 6, column "Record", where it was written:

$1,2,11,12,16,17,19-25$ and 77 [MN 55699, UnB 1603-UnB1607]

Should read:

$1,2,11,12,16,17,19-25$ and 77 [MN 53699, UnB 1603-UnB 1607]

Table 1, page 9, column "Record", where it was written:

12, 17, 19, 22, 23, 79, 99 [MN 43003, UnB 2636]

Should read:

12, 17, 19, 22, 23, 79, 99 [MN 43004, UnB 2636]

Table 1, page 10, column "Record", where it was written:

6 [MN 2615, MN 22583, MZUSP 25304]

Should read:

6 [MN 2615, MN 22853, MZUSP 25304]

Table 1, page 10, column "Record", where it was written:

105, 106, 112 [MN 437, AMNH 134562]

Should read:

105, 106, 112 [MN 32445, AMNH 134562]

Table 1, page 10, column "Record", where it was written:

13 [MN 62579, UnB 1706]

Should read:

13 [MN 62570, UnB 1706]

Table 1, page 10, column "Record", where it was written:

91, 113 [MN 62174]

Should read:

91, 113 [MN 62179]

Table 1, page 10, column "Record", where it was written:

3, 13, 79, 92, 104,108 [MN 67089]

Should read:

3, 13, 79, 92, 104,108 [MN 67086]

Table 1, page 11, column "Record", where it was written:

1, 3, 106 [UnB 2084, MN 46619, MN 71657]

Should read:

1, 3, 106 [CRB 1115, UNB 1174, UNB 1180] 